\title{
Malignant Melanoma Metastasis to Sigmoid Colon: New Endoscopic Appearance Detected for the First Time
}

\author{
Ugur Kesici ${ }^{1,2,3}$ \\ ${ }^{1}$ Department of General Surgery, Health Science University, Sultan II, Abdulhamid Han Training and Reseach Hospital, Istanbul, \\ Turkey. \\ ${ }^{2}$ Department of General Surgery, Faculty of Medicine, Beykent University, İstanbul, Turkey \\ ${ }^{3}$ Department of General Surgery, Medipol Bahcelievler Nisa Hospital, Istanbul, Turkey
}

\begin{abstract}
Malignant melanoma (MM) develops as a result of malignant transformation of melanocytes. It accounts for $4 \%$ of all skin cancers. MM metastases usually occur in regional lymph nodes, bones and central nervous system. In this case report, a case of a 50-year male, who was found to have MM infiltration on colonoscopy performed for the etiology of anemia, is discussed. The patient underwent gastroscopy and colonoscopy for the determination of the primary tumor. Colonoscopic examination showed multiple submucosal hyperpigmented areas and a sessile polyp with a diameter of 4-5 mm in the sigmoid colon. Biopsies of hyperpigmented lesions were consistent with MM infiltration. Gastrointestinal tract (GIT) metastases are rare in MM. In literature, MM metastases to GIT have endoscopic appearances of 3 types. Typically, on endoscopy, ulceration with nodule or mass is visualised. However, in this case, an appearance of 'only submucosal melanosis without mass or nodule' was identified, distinct from previously described three endoscopic views and it was verified histopathologically. This case will help increase awareness of endoscopists in terms of being careful to look for MM metastasis on endoscopic examinations, which may be defined as $4^{\text {th }}$ type of endoscopic appearance.
\end{abstract}

Key Words: Malignant melanoma, Metastasis, Colon, Endoscopy.

How to cite this article: Kesici U. Malignant Melanoma Metastasis to Sigmoid Colon: New Endoscopic Appearance Detected for the First Time. J Coll Physicians Surg Pak 2020; 30(11):1223-1225.

\section{INTRODUCTION}

Malignant melanoma (MM) develops as a result of malignant transformation of melanocytes. It accounts for $4 \%$ of all skin cancers. ${ }^{1}$ It usually occurs in the fourth to sixth decades of life. Its localisation varies depending on gender. It is frequently seen on the trunk of males and the lower extremities of females. ${ }^{2} \mathrm{MM}$ is the most aggressive and fatal skin cancer. The main problem in MM is misdiagnosis and the potential for early metastasis. ${ }^{3} \mathrm{MM}$ metastases usually occur in regional lymph nodes, bones and central nervous system. ${ }^{1}$

In this case report, a new endoscopic appearance, that was detected for the first time in the case of primary cutaneous MM diagnosed with a very rare sigmoid colon metastasis, is discussed in the light of literature.

Correspondence to: Dr. Ugur Kesici, Health Science University, Sultan II. Abdulhamid Han Training and Reseach Hospital, Department of General Surgery, İstanbul, Turkey

E-mail: ugurkesici77@mynet.com

Received: September 17, 2019; Revised: November 05, 2019; Accepted: November 14, 2019

DOI: https://doi.org/10.29271/jcpsp.2020.11.1223

\section{CASE REPORT}

A 50-year male, who was found to have MM infiltration on colonoscopy performed for the etiology of anemia, was investigated. The laboratory tests of the patient, carried out in another centre due to the complaint of weakness, revealed anemia; and abdominal computed tomography (CT) revealed multiple metastatic lesions in the liver, lung, bone, and peritoneal region; and mural thickening at the hepatic flexure level of the colon(Figure 1).

The patient's physical examination revealed pale sclerae. In the right periorbital region, a large hemangioma extending to the temporal region was noted. A hyperpigmented nevus measuring about $5 \times 6 \mathrm{~cm}$ was present in the right temporal region. The patient underwent gastroscopy and colonoscopy for the determination of the primary tumor. The patient's gastroscopy and colonoscopy showed no evidence of primary malignancy. However, colonoscopic examination showed multiple submucosal hyperpigmented areas and a sessile polyp with a diameter of 4-5 $\mathrm{mm}$ in the sigmoid colon. Polypectomy result was reported as tubular adenoma; whereas, the biopsy of hyperpigmented lesions was consistent with MM infiltration. The colonoscopy image of the patient is shown in Figure 2.

The patient was referred to the Oncology Clinic formedical treatmentbecause of the presence of multiple organ metastasis. 


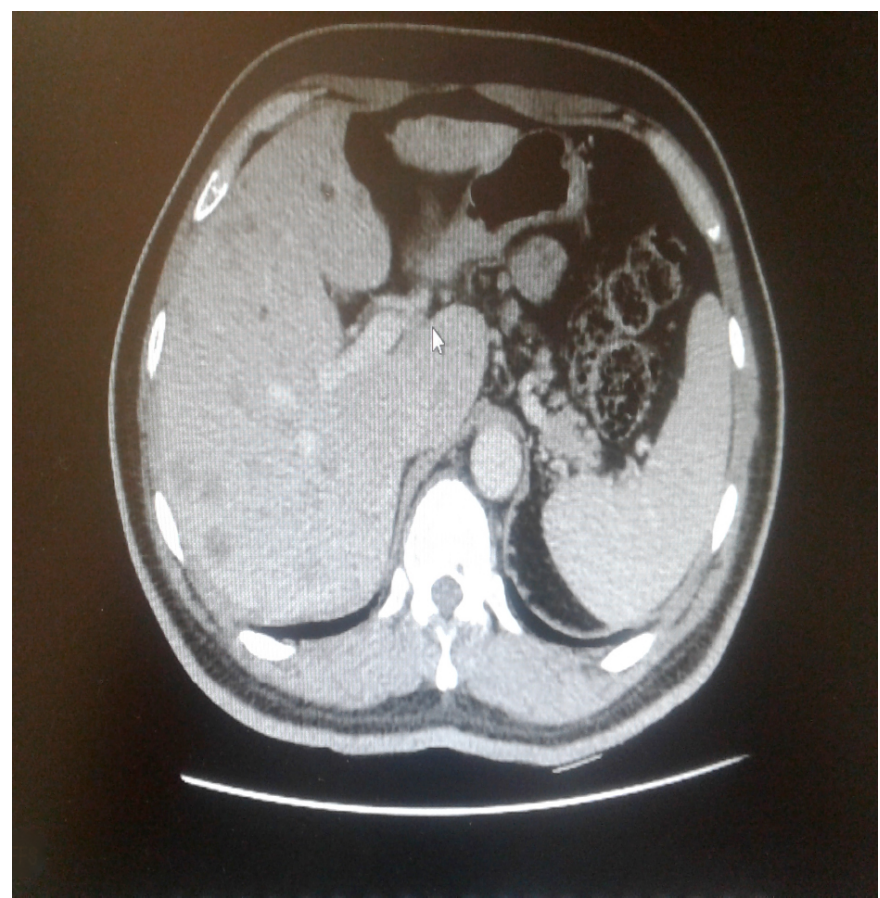

Figure 1: Abdominal CT image of the patient.

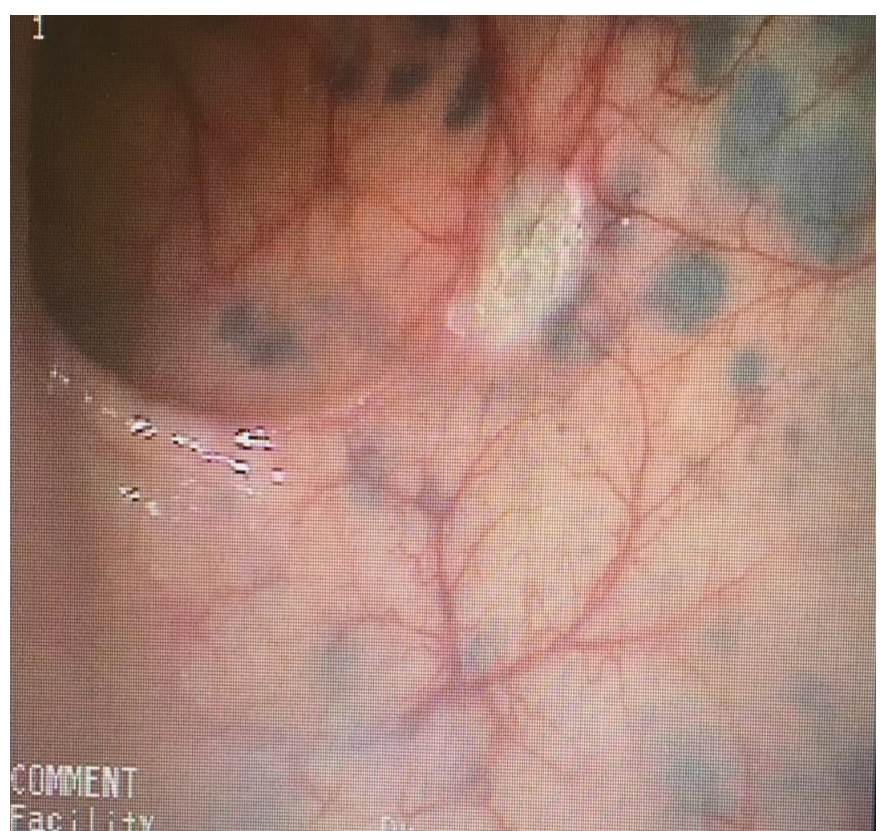

Figure 2: Colonoscopy image of the patient.

\section{DISCUSSION}

MM mainly metastasises to regional lymph nodes via the lymphatic route. Therefore, lymph node metastasis is considered as the most important prognostic factor. ${ }^{2}$ Distant metastases frequently arise in different skin areas, subcutaneous tissues, lungs, and liver. ${ }^{4}$ On the other hand, GIT metastases are rare. ${ }^{5}$ Metastatic GIT MMs are usually extraluminal and usually present with obstruction, intussusception and intraabdominal mass. ${ }^{6}$ In this case, unlike other cases in the literature, a submucosal hyperpigmented lesion was identified. In general, metastatic GIT MMs are clinically asymptomatic and usually diagnosed during autopsy. Therefore, it is recommended to keep MM metastasis in mind and to examine the mucosa very carefully, especially in patients with a history of MM undergoing endoscopic examination due to GIT symptoms and anemia. ${ }^{7}$ In the study by Drevelegkas et al. ${ }^{5}$, it was reported that there were 4 cases of cutaneous MM diagnosed with colon metastasis as a result of biopsy. In this case, the patient was diagnosed with metastatic spread of primary cutaneous MM by biopsy performed during colonoscopic examination for the etiology of anemia.

Endoscopically, tumor metastases may be classified into three types: ulcerated melanotic nodules arising on normal rugae, submucosal masses with ulcerations, and mass lesions with necrosis and melanosis. ${ }^{7,8}$ However, in this case, only submucosal melanosis was detected in the patient in the absence of mucosal/submucosal mass or ulceration. Since this endoscopic view is different from the three types of endoscopic appearance described in the literature, it qualifies to be reported as the $4^{\text {th }}$ type of endoscopic MM metastasis appearance. There is no other case reported in the literature with similar endoscopic appearance. It is recommended that this case be recorded as type 4 endoscopic view of only submucosal melanosis without mass or nodule. The result obtained from this case report reveals that mucosa should be examined very carefully, especially in GIT endoscopic examinations performed for a suspicion of malignancy; and MM metastasis should be kept in mind in the presence of submucosal melanosis.

Wide local excision and sentinel lymph node biopsy (SLNB) is recommended for the treatment of cutaneous MM. Elective lymph node dissection is recommended in the presence of positive nodal involvement in SLNB. ${ }^{9}$ The basic approach to MM metastases is to perform metastatectomy if the primary disease is under control, isolated metastasis is present, complete resection is possible, and there is no surgical risk. ${ }^{2}$ However, it is reported to be beneficial for mortality in GIT metastases, even if resection is incomplete. ${ }^{7}$ The limits of surgery are not clearly known in GIT metastases. The role of chemotherapy in metastatic GIT MM is uncertain and radiotherapy is useful for palliation. ${ }^{10}$ Since the patient in this case had multiple metastatic foci in multiple organs, surgical intervention was not planned. Melanoma is an aggressive tumour and metastatic disease has a very poor prognosis. ${ }^{4}$

$\mathrm{MM}$ is the most aggressive and fatal skin cancer with a potential of misdiagnosis and early metastasis. Metastases to GIT are rare and endoscopically appear to be of three different types. This case may be designated as type 4 endoscopic appearanceof MM mestastases in the GIT.

\section{PATIENTS' CONSENT:}

Institutional consent has been obtained.

\section{CONFLICT OF INTEREST:}

The author declared no conflict of interest.

\section{AUTHOR'S CONTRIBUTION:}

UK: Colonoscopic examination and biopsy, literature review, study design, and article. 


\section{REFERENCES}

1. Dalar L, Karasulu AL, Altın S, Sokucu SN, Duger M, Urer N. Diode laser therapy for endobronchial malignant melanoma metastasis leading bilateral main bronchus obstruction. Tüberküloz ve Toraks Dergisi 2010; 58(4):444-9.

2. Samancilar O, Kaya SO, Akcay O, Akcam TI, Ceylan KC, Yener AG. Video-assisted thoracoscopic surgery lobectomy for pulmonary malignant melanoma metastasis. Eurasian J Med 2015; 47(3):223-5. doi: 10.5152/eurasianjmed. 2015.75.

3. Abbas O, Miller DD, Bhawan J. Cutaneous malignant melanoma: Update on diagnostic and prognostic biomarkers. Am J Dermatopathol 2014; 36(5):363-9. doi: 10.1097/DAD.0b013e31828a2ec5.

4. Halkias C, Sloane J, Ben-Gashir M, Bashir G. Synchronous metastatic omental melanoma and colonic adenocarcinoma: A case report. BMC Res Notes 2015; 8:125. doi: 10.1186/s13104-015-1099-7.

5. Drevelegkas K, Bangeas P, Paramythiotis D, Andrews T,
Zakeri S. Metastatic spread of cutaneous melanoma to the sigmoid colon: A rare but important consideration. Hippokratia 2017; 21(4):194-6.

6. Ulger BV, Erbiş H, Turkoğlu M, Yılmaz EE, Gul M, Aliosmanoglu I, et al. Intestinal melanoma: Case report. Turk J Colorectal Dis 2015; 25:136-9.

7. Wong K, Serafi SW, Bhatia AS, Ibarra I, Allen EA. Melanoma with gastric metastases. J Community Hosp Intern Med Perspect 2016; 6(4):31972. doi: 10.3402/jchimp.v6.31972.

8. Blecker D, Abraham S, Furth EE, Kochman ML. Melanoma in the gastrointestinal tract. Am J Gastroenterol 1999; 94(12):3427-33. doi: 10.1111/j.1572-0241.1999.01604.x

9. Sahin I, Aykan A, Dogan A, Zor F, Öztürk S, Eski M, et al. Retrospective evaluation of malign melanoma patient. Gülhane Tıp Derg 2011; 53:177-81.

10. Fernández-Albornoz M, Irarrázaval-Espinoza J, LarachKattan A, Espíndola-Silva L. Anorectal melanoma associated with colonic metastasis. Rev Esp Enferm Dig 2014; 106(4):281-2. 